
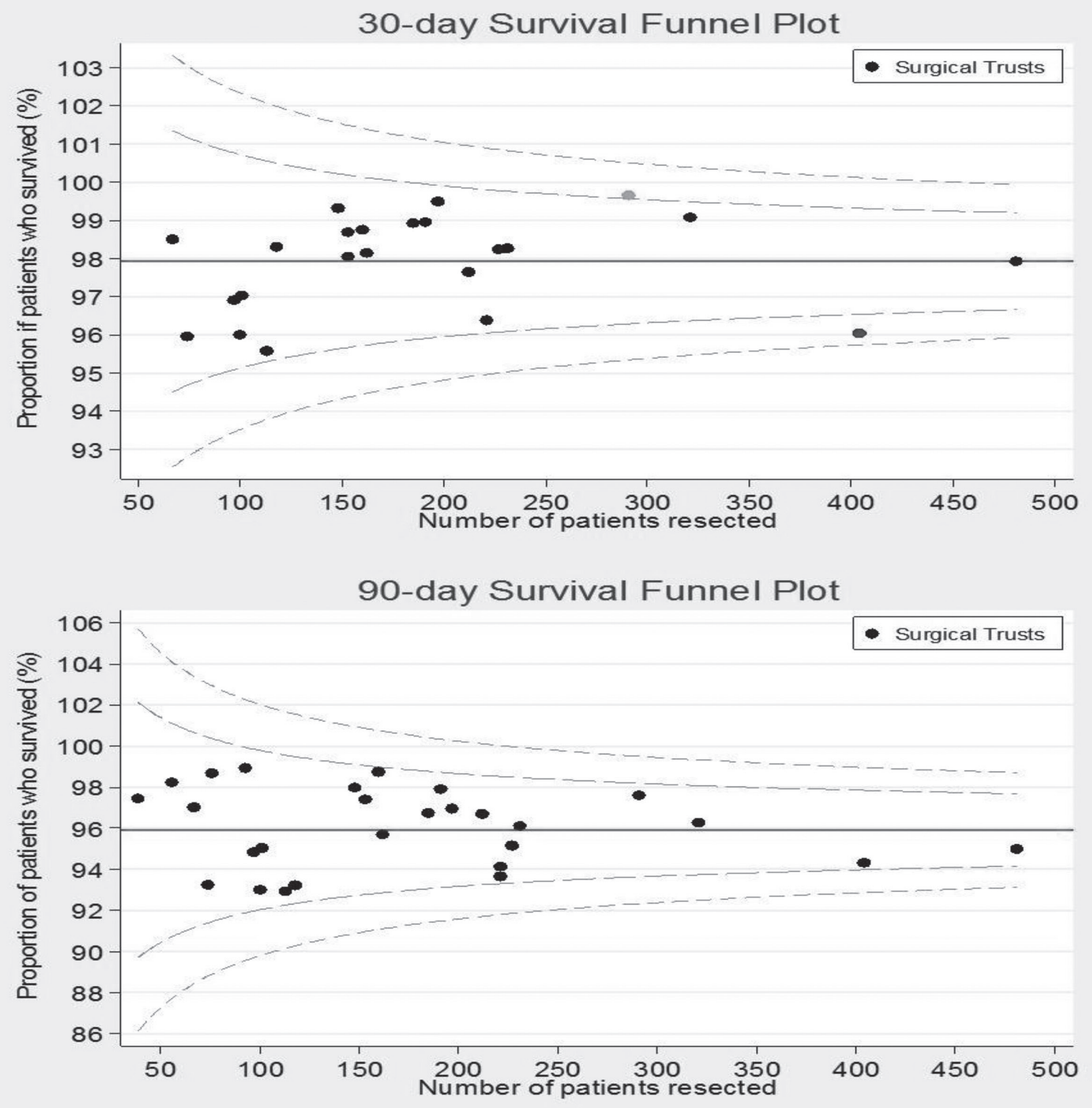

Abstract S60 Figure 130 and 90 day survival by trust

\section{S61 RISK FACTORS AND SHORT-TERM OUTCOMES OF DEVELOPING POSTOPERATIVE PULMONARY COMPLICATIONS AFTER VATS LOBECTOMY}

${ }^{1} \mathrm{P}$ Agostini, ${ }^{2}$ ST Lugg, ${ }^{1} \mathrm{~K}$ Adams, ${ }^{3} \mathrm{~T}$ Smith, ${ }^{1} \mathrm{M}$ Kalkat, ${ }^{1} \mathrm{~PB}$ Rajesh, 'RS Steyn, ${ }^{1} \mathrm{~B}$ Naidu, ${ }^{3}$ A Rushton, ${ }^{1} \mathrm{E}$ Bishay. ${ }^{1}$ Department of Thoracic Surgery, Heart of England NHS Foundation Trust, Birmingham, UK; ${ }^{2}$ Institute of Inflammation and Ageing, University of Birmingham, Birmingham, UK; ${ }^{3}$ School of Sport, Exercise and Rehabilitation Sciences, University of Birmingham, Birmingham, UK

\subsection{6/thoraxjnl-2016-209333.67}

Introduction Postoperative pulmonary complications (PPC), such as pneumonia and atelectasis are associated with poor outcomes following thoracotomy and lung resection, with risk factors identified. $^{1,2}$ Video-assisted thoracoscopic surgery (VATS) is increasingly performed, however, there are varying reports regarding the incidence of PPC with little is known about their effect on short-term outcomes or potential risk factors.

Methods A prospective observational study of consecutive patients undergoing VATS lobectomy was performed in a regional centre (2012-2016). Exclusion criteria included re-do VATS/completion lobectomy. All patients received physiotherapy assessment/intervention as necessary from postoperative day 1 (POD1). The presence of PPC was determined daily using the Melbourne Group Scale. Outcomes included hospital length of stay (LOS), intensive therapy unit (ITU) admission and hospital mortality. 
Results 287 patients underwent VATS lobectomy, 2 patients undergoing completion lobectomy were excluded. Of 285 patients; 137 were male (48\%), median (IQR) age of 69 years $(13)$ and mean $( \pm S D)$ FEV1 of $87 \%( \pm 19)$. PPC developed in 21 patients (7.4\%); the median day that PPC developed was postoperative day 3 (Figure 1). Patients who developed a PPC had a significantly longer hospital LOS (4 vs 3 days), higher rate of ITU admission $(25 \%$ vs $0 \%)$ and higher hospital mortality ( $14 \%$ vs $0 \%)(p<0.001)$. Current smoking and COPD diagnosis were significantly different on univariate analysis $(p<0.05)$, but on forward stepwise logistic regression, only current smoking was a significant independent risk factor for PPC $(p=0.015)$. Those with PPC required significantly more physiotherapy contacts/ time, with more specific pulmonary therapy and emergency outof-hours therapy.

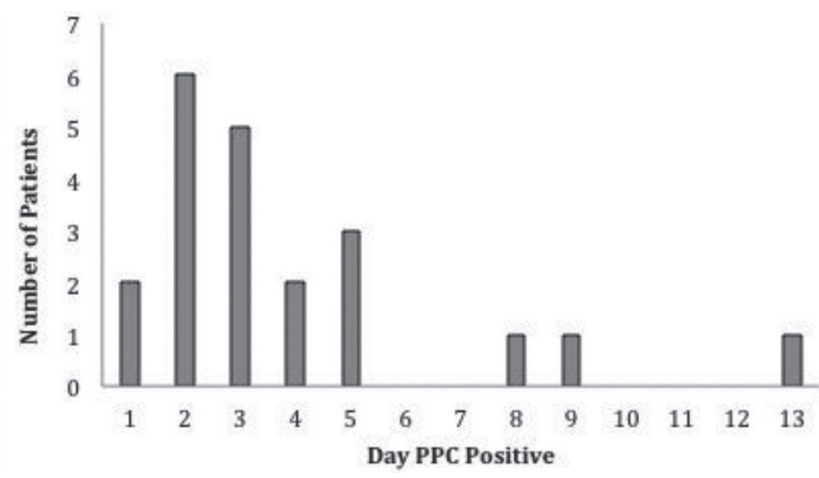

Abstract S61 Figure 1 Day PPC detected following surgery

Conclusions Patients undergoing VATS remain at risk of developing a PPC associated with significantly worse short-term morbidity and mortality. Patients that develop a PPC following VATS required increased postoperative physiotherapy compared to non-PPC patients. Current smoking is an independent risk factor for PPC development following VATS, thus vigorous addressing of preoperative smoking cessation is urgently needed.

\section{REFERENCES}

1 Agostini $\mathrm{P}$, et al. Postoperative pulmonary complications following thoracic surgery: are there any modifiable risk factors? Thorax 2010;65(9):815-8.

2 Lugg ST, et al. Long-term impact of developing a postoperative pulmonary complication after lung surgery. Thorax 2016;71(2):171-6.

\section{S62 ADEQUACY OF INTRA-OPERATIVE LYMPH NODE SAMPLING DURING SURGICAL RESECTION OF NSCLC: INFLUENCING FACTORS AND ITS RELATIONSHIP TO SURVIVAL}

T Edwards, H Balata, C Tennyson, P Foden, P Bishop, M Jones, P Krysiak, K Rammohan, R Shah, P Crosbie, R Booton, M Evison. University Hospital of South Manchester, Manchester, UK

10.1136/thoraxjnl-2016-209333.68

Background Adequate intra-operative lymph node sampling is a fundamental part of lung cancer surgery but adherence to standards, particularly in the United Kingdom is not well known. The
International Association for the Study of Lung Cancer (IASLC) has defined adequate lymph node sampling as: at least 3 mediastinal lymph node stations, station 7 in all cases, station 5/6 with left upper lobe tumours and station 9 with lower lobe tumours; the sampling of at least 3 hilar lymph node stations is also recommended This study sought to measure the adequacy of intra-operative lymph node sampling at a regional Lung Cancer Centre, the factors which may influence this and impact on survival.

Methods A retrospective review of the pathological reports for all patients who underwent surgical resection for NSCLC at the University Hospital of South Manchester between 2011 and $2014(\mathrm{n}=1407)$ was performed. Lung cancer resection specimens are reported in line with the minimum dataset defined by the Royal College of Pathology and contain a record of all lymph node stations sampled intra-operatively and the histological findings from these lymph nodes. The influence of clinical variables on adequacy of lymph node sampling was investigated and survival data was obtained from national death registries.

Results Adequate intra-operative lymph node sampling increased significantly from $13 \%(23 / 173)$ in 2011 to $51 \%(224 / 437)$ in 2014 coinciding with a dramatic increase in the volume of lung cancer surgery (Table 1). Secondary analysis also revealed that patients with a low or high T-stage, undergoing sublobar resections and undergoing left sided resections have significantly higher rates of inadequate lymph node sampling. Overall, there was no statistically significant difference in survival between patients with adequate and inadequate intra-operative lymph node sampling.

Conclusion This study provides a much-needed benchmark of current thoracic surgical practice in lung cancer in the UK and provides important granularity to facilitate changes to improve adequacy of staging. Further improvement is needed to meet the standards as defined by the IASLC, however, what constitutes an "acceptable" level of adequacy is yet to be defined and this impact on survival is not clear.

Abstract S62 Table 1 Intra-operative nodal sampling during resection of NSCLC at UHSM (2011-14)

\begin{tabular}{|c|c|c|c|c|c|c|}
\hline \multirow[t]{2}{*}{ Measure } & & \multicolumn{4}{|c|}{ Year of surgery } & \multirow{2}{*}{$\begin{array}{l}2011 / 12 \text { vs } \\
2013 / 14 \\
\text { p-value }\end{array}$} \\
\hline & & \multirow{2}{*}{$\frac{2011}{173}$} & \multirow{2}{*}{$\begin{array}{l}2012 \\
333\end{array}$} & \multirow{2}{*}{$\begin{array}{l}2013 \\
464\end{array}$} & \multirow{2}{*}{$\begin{array}{l}2014 \\
437\end{array}$} & \\
\hline Total number of NSCLC resections & $n$ & & & & & \\
\hline Overall proportion of adequate & $\%$ & $13 \%$ & $22 \%$ & $38 \%$ & $51 \%$ & $<0.0001$ \\
\hline nodal sampling & (n) & $(23)$ & (73) & (174) & (224) & \\
\hline$\geq 3$ mediastinal LN stations & $\%$ & $17 \%$ & $31 \%$ & $47 \%$ & $60 \%$ & $<0.0001$ \\
\hline sampled & (n) & (30) & $(103)$ & (220) & (262) & \\
\hline \multirow[t]{2}{*}{ Station 7 sampled } & $\%$ & $36 \%$ & $46 \%$ & $63 \%$ & $56 \%$ & $<0.0001$ \\
\hline & (n) & $(63)$ & (154) & (290) & (244) & \\
\hline \multirow[t]{2}{*}{ Station $5 / 6$ in LUL tumours } & $\%$ & $72 \%$ & $73 \%$ & $76 \%$ & $84 \%$ & $<0.15$ \\
\hline & (n) & $(42)$ & $(72)$ & (104) & (95) & \\
\hline \multirow[t]{2}{*}{ Station 9 in lower lobe tumours } & $\%$ & $49 \%$ & $52 \%$ & $60 \%$ & $65 \%$ & 0.008 \\
\hline & (n) & (37) & $(66)$ & (124) & (114) & \\
\hline \multirow[t]{2}{*}{ Proportion of multi-station N2 } & $\%$ & $5 \%$ & $4 \%$ & $5 \%$ & $4 \%$ & \\
\hline & (n) & (8) & (12) & $(25)$ & $(17)$ & \\
\hline
\end{tabular}

